\title{
Transient positivity of anti-tissue transglutaminase IgA autoantibody in febrile children: a case-control study
}

\author{
Iraj Shahramian ${ }^{\ominus}$, Mehrdad Salahifar ${ }^{\oplus}$, Majid Reza Akbarizadeh ${ }^{\bullet}$ \\ Mohammad Hasan Mohammadi ${ }^{\ominus}$, Ali Bazi ${ }^{\ominus}$ \\ Pediatric Gastroenterology and Hepatology Research Center, Zabol University of Medical Sciences, Zabol, Iran.
}

\begin{abstract}
Background. Fever is a physiological response activated by integrative interactions between the neuronal and immune systems. The association of fever with the development of autoantibodies against various self-antigens is controversial. We here evaluated if fever was associated with increased levels of anti-tissue transglutaminase (tTG) IgA autoreactive antibodies in children.
\end{abstract}

Methods. This was a case-control study performed the Amir-Al-Momenin Hospital of Zabol City from January to December 2018. Febrile children $(\mathrm{N}=135)$ and apparently healthy counterparts $(\mathrm{N}=135)$ were included. Total IgA and anti-tTG IgA were measured by ELISA.

Results. From 270 children evaluated, 144 (53.6\%) and 126 (46.4\%) were males and females, respectively. The mean age was $4.7 \pm 2.6$ years. The mean total IgA titer was $208 \pm 100 \mathrm{mg} / \mathrm{dl}$, and the mean anti-tTG IgA titer was $15.9 \pm 68 \mathrm{mg} / \mathrm{dl}$. There was a significant difference in the mean titer of anti-tTG IgA between apparently healthy controls $(1.97 \pm 1.12 \mathrm{mg} / \mathrm{dl})$ and febrile children $(30.2 \pm 94.9 \mathrm{mg} / \mathrm{dl}, \mathrm{p}=0.002)$. Positivity for anti-tTG IgA was observed in $16(11.8 \%)$ out of 135 febrile children while no subject in the control group had positive results. One out of the 16 positive cases showed persistent elevated levels after fever disappearance. On biopsy examination, this child was confirmed to have celiac disease.

Conclusions. We showed that fever can trigger the production of anti-tTG IgA autoantibody in children. It is recommended for pediatricians to be vigilant in interpreting anti-tTG IgA results during fever episodes and repeat positive cases after the cease of fever. It is also recommended to reassess anti-tTG IgA seropositivity in other clinical settings in future studies.

Key words: fever, tissue transglutaminase, autoantibody, immune system, celiac disease.

Fever is a physiological response activated by integrative interactions between the neuronal and immune systems. ${ }^{1}$ Fever is in fact a regulated boost in the core body temperature to combat microorganisms and inhibit their growth within human tissues and cells. In this manner, fever is considered to be a major factor affecting physio-pathological features and the clinical course of human infectious diseases. ${ }^{1}$

$凶$ Ali Bazi

m.baziali@gmail.com

Received 26th February 2019, revised 19th May 2020, 18th July 2020, accepted 27th July 2020.
Overall, fever is a multifactorial adaptive response intercalating with various body systems. The role of immune system in promoting and regulating fever upon infections has been highlighted. ${ }^{2}$ Immune components including immune cells and various cytokines are bridges linking immunological reactions to the nervous system to induce fever. These two systems act in a highly intercalated manner to promote a vigilant response against stresses and potential environmental threats. ${ }^{3}$

The cytokines involved in regulating the interaction between immune and nervous systems are known as "endogenous pyrogens". A wide variety of inflammatory cytokines 
including tumor necrosis factor (TNF), interleukin (IL)-1, IL-6, and interferons can play a role as pyrogens. The main function of these mediators in neuronal system is to induce the production of prostaglandins which subsequently lead to hyperthermia and fever. However, induction of fever by pyrogens has been suggested to involve other parallel mechanisms which are poorly understood. The role of immune system receptors such as toll-like receptors has been suggested in these processes. ${ }^{4,5}$ Nevertheless, these inflammatory cytokines also exert vast influences on immune system function. ${ }^{6,7}$ Accordingly, fever induced inflammatory cytokines may promote exaggerated immune response leading to detrimental effects against self-tissues and autoimmunity. ${ }^{8,9}$ Nonetheless, the association of fever with the development of autoantibodies against many self-antigens is unknown. In the present study, we evaluated if fever is associated with increased levels of antitissue transglutaminase (tTG) IgA autoreactive antibodies in febrile children.

\section{Material and Methods}

This case control study was performed in the Amir-Al-Momenin Hospital of Zabol City from January to December 2018. All children fulfilling our inclusion criteria were considered as the study population. Control subjects were recruited from age- and sex-matched apparently healthy children visiting the clinic for periodical checkups. The study was approved by the local Ethics Committee in Research of Zabol University of Medical Sciences (20th November 2018, Code: Ir.Zbmu.Rec.1397.115). Informed consent was acquired from the children's parents.

\section{Inclusion and exclusion criteria}

Children hospitalized in the pediatric ward of the hospital due to fever were included in the case group. Those with a previous diagnosis of celiac disease, a family history of celiac disease or other autoimmune diseases, and patients under treatment with anti-inflammatory drugs were excluded from both the case and control groups.

\section{Sample size}

The sample size was calculated based on the below formula.

$\mathrm{n}=\left(\mathrm{Z}_{\alpha / 2}+\mathrm{Z}_{\beta}\right)^{2 *}\left(\mathrm{p}_{1}\left(1-\mathrm{p}_{1}\right)+\mathrm{p}_{2}\left(1-\mathrm{p}_{2}\right)\right) /\left(\mathrm{p}_{1}-\mathrm{p}_{2}\right)^{2}$

In this equation, $Z_{\alpha / 2}$ (1.96) represented the coefficient of significance threshold $(p<0.05)$. The $Z_{\beta}$ was the coefficient related to the power of study $(80 \%)$ and considered as 0.84 . P1 and P2 represented the expected frequencies of positivity for anti-tTG IgA in the case and control groups ( $2 \%$ and $4 \%$, respectively). Accordingly, the sample size for each group was obtained $(\mathrm{N}=135)$.

\section{Data acquisition}

The demographic data and the past clinical history were obtained by interviewing parents. After that, blood samples $(5 \mathrm{ml})$ were drawn from case and control children. The serum samples were separated in the hospital laboratory, and anti-tTG IgA and total IgA levels were determined using specific ELISA kits (Pars Azmoun Co, Iran).

\section{Statistical analysis}

SPSS 16 (Chicago Inc, USA) was used for statistical procedures. Shapiro-Wilk test was applied to screen the normal distribution. Independent sample Student t-test and Chisquare test were used for inferential statistics. $\mathrm{P}$ value $<0.05$ was considered as the statistical significance threshold.

\section{Results}

From 270 children evaluated, 144 (53.6\%) and 126 (46.4\%) were males and females, respectively. The mean age was $4.7 \pm 2.6$ years, and the mean weight was $19.7 \pm 10.9 \mathrm{~kg}$. Fever was the constant clinical finding in all the children in the case group. In 106 (78.5\%) of the patients, fever was 
accompanied with cough, and in 7 (5.1\%) with diarrhea. Gastroenteritis and malnutrition each were observed in one patient. Recurrent fever was observed in 9 (6.6\%). Mean hemoglobin level was $13.9 \pm 1.9 \mathrm{~g} / \mathrm{dl}$, and the mean values of AST and ALT were $14.4 \pm 2.1 \mathrm{IU} / \mathrm{L}$ and $11.8 \pm 2.1$ IU/L, respectively (Table I).

The mean total $\operatorname{IgA}$ value ranged from 7 to 677 $\mathrm{mg} / \mathrm{dl}$ with the mean value of $208 \pm 100 \mathrm{mg} /$ dl. The mean anti-tTG IgA was obtained 15.9 $\pm 68 \mathrm{mg} / \mathrm{dl}$. There was a significant difference in the mean titer of anti-tTG IgA between apparently healthy controls and febrile children (Table II). Based on the reference threshold, positivity for anti-tTG was noted in 16 out of $135(11.8 \%)$ febrile while no subject in controls had positive results. From these 16 children, one case showed persistent elevated levels after fever disappearance (i.e. after discharge). On follow up biopsy examination, this child was confirmed to have celiac disease.
There were no significant differences comparing demographic or clinical variables between patients with positive or negative anti-tTG results except for the levels of alkaline phosphatase enzyme $(p=0.01$, Table III).

\section{Discussion}

The main goal of the present study was to evaluate the levels of total $\operatorname{IgA}$ and autoreactive anti-tTG $\operatorname{IgA}$ antibodies in febrile children and compare them with healthy counterparts. Overall, 16 (11.8\%) of 135 febrile children revealed positivity for anti-tTG IgA. One patient preserved positive results on follow-up which later was diagnosed with celiac disease based on intestinal biopsy examination. Therefore, the elevation of autoreactive anti-tTG IgA was temporary in most of the patients.

Although we found no similar studies assessing anti-tTG IgA autoantibodies in febrile children,

Table I. Demographic, clinical and laboratory features in febrile and non-febrile healthy children.

\begin{tabular}{|c|c|c|c|}
\hline Parameters & Febrile $(\mathrm{N}=135)$ & Non-febrile $(\mathrm{N}=135)$ & $\mathrm{P}$ \\
\hline Male/female, n/n (\%/\%) & $66 / 69(49.6 / 50.4)$ & $77 / 58(57.5 / 42.5)$ & 0.13 \\
\hline Age (years) & $5.8 \pm 2.2$ & $3.6 \pm 2.4$ & $<0.001$ \\
\hline Weight (kg) & $21.8 \pm 11.6$ & $17.5 \pm 9.7$ & 0.002 \\
\hline White blood cell $\left(10^{3} / \mu \mathrm{l}\right)$ & $12.6 \pm 1.7$ & $13.6 \pm 1.5$ & $<0.001$ \\
\hline Red blood cell $\left(10^{6} / \mu \mathrm{l}\right)$ & $4.8 \pm 0.3$ & $4.8 \pm 0.2$ & 0.51 \\
\hline Hemoglobin (g/dl) & $13.7 \pm 2.6$ & $14.1 \pm 0.9$ & 0.13 \\
\hline Hematocrit (\%) & $38.9 \pm 1.9$ & $40.1 \pm 1.8$ & $<0.001$ \\
\hline Mean cell volume (fl) & $79.5 \pm 7.2$ & $80.5 \pm 2.1$ & 0.11 \\
\hline Mean cell hemoglobin (pg) & $28.8 \pm 3.2$ & $26.9 \pm 0.6$ & $<0.001$ \\
\hline Platelet $\left(10^{3} / \mu \mathrm{l}\right)$ & $356.8 \pm 122.2$ & $218.3 \pm 61.7$ & 0.005 \\
\hline Blood urea nitrogen (mg/dl) & $14.1 \pm 2.1$ & $14.7 \pm 1.3$ & 0.21 \\
\hline Creatinine (mg/dl) & $0.62 \pm 0.79$ & $0.54 \pm 0.17$ & 0.01 \\
\hline Aspartate aminotransferase (IU/L) & $14.1 \pm 2.7$ & $14.8 \pm 1.3$ & 0.26 \\
\hline Alanine aminotransferase (IU/L) & $11.6 \pm 2.7$ & $11.9 \pm 1.4$ & $<0.3$ \\
\hline Alkaline phosphatase (IU/L) & $139.7 \pm 79.8$ & $91.6 \pm 45.9$ & 0.73 \\
\hline Erythrocyte sedimentation rate $(\mathrm{mm} / \mathrm{h})$ & $13.7 \pm 5.2$ & $13.4 \pm 4.2$ & 0.52 \\
\hline
\end{tabular}

Table II. The mean titers of total IgA and anti-tTG IgA antibodies in febrile and non-febrile children.

\begin{tabular}{lccc}
\hline Parameters & Febrile $(\mathrm{N}=135)$ & Non-febrile $(\mathrm{N}=135)$ & $\mathrm{P}$ \\
\hline Total IgA $(\mathrm{mg} / \mathrm{dl})$ & $211.5 \pm 120.7$ (range: $7-677)$ & $204.5 \pm 74.9$ (range: $71-492)$ & 0.59 \\
Anti-tTG IgA $(\mathrm{mg} / \mathrm{dl})$ & $30.2 \pm 94.9$ (range: $0.11-542)$ & $1.97 \pm 1.12$ (range: 0.21-5.8) & 0.002 \\
\hline
\end{tabular}

tTG: tissue transglutaminase 
Table III. Comparisons of demographic, clinical and laboratory features between anti-tTG IgA positive and negative patients among febrile children.

\begin{tabular}{lccc}
\hline \multirow{2}{*}{ Parameters } & \multicolumn{2}{c}{ Anti-tTG IgA } & \multirow{2}{*}{$\mathrm{p}$} \\
\cline { 2 - 3 } & Positive $(\mathrm{N}=16)$ & Negative $(\mathrm{N}=119)$ & $0.2^{*}$ \\
Male/female, $\mathrm{n} / \mathrm{n}(\% / \%)$ & $10 / 6(62.5 / 37.5)$ & $56 / 63(47.1 / 52.9)$ & $0.6^{*}$ \\
Gastric symptoms (Yes), $\mathrm{n}(\%)$ & $1(7.1)$ & $18(15.1)$ & $0.47^{*}$ \\
Recurrence of fever (Yes), $\mathrm{n}(\%)$ & 0 & $9(7.6)$ & 0.24 \\
Age (years) & $6.5 \pm 1.7$ & $5.8 \pm 2.3$ & 0.41 \\
Weight $(\mathrm{kg})$ & $24.1 \pm 12.2$ & $21.5 \pm 11.5$ & 0.69 \\
White blood cell $\left(10^{3} / \mu \mathrm{l}\right)$ & $12.8 \pm 1$ & $12.5 \pm 1.8$ & 0.92 \\
Red blood cell $\left(10^{6} / \mu \mathrm{l}\right)$ & $4.8 \pm 0.3$ & $4.8 \pm 0.3$ & 0.23 \\
Hemoglobin $(\mathrm{g} / \mathrm{dl})$ & $15.6 \pm 6.7$ & $13.4 \pm 0.8$ & 0.42 \\
Hematocrit $(\%)$ & $40 \pm 2$ & $38.8 \pm 1.8$ & 0.47 \\
Mean cell volume (fl) & $80.7 \pm 2.5$ & $79.3 \pm 7.7$ & 0.35 \\
Mean cell hemoglobin $(\mathrm{pg})$ & $29.5 \pm 1$ & $28.7 \pm 3.4$ & 0.85 \\
Platelet $\left(10^{3} / \mu \mathrm{l}\right)$ & $362 \pm 90.2$ & $356 \pm 127.6$ & 0.34 \\
Blood urea nitrogen $(\mathrm{mg} / \mathrm{dl})$ & $13.6 \pm 2.7$ & $14.1 \pm 2$ & 0.68 \\
Creatinine $(\mathrm{mg} / \mathrm{dl})$ & $0.58 \pm 0.17$ & $0.63 \pm 85$ & 0.52 \\
Aspartate aminotransferase $(\mathrm{IU} / \mathrm{L})$ & $14.5 \pm 2.7$ & $14 \pm 2.7$ & 0.09 \\
Alanine aminotransferase $(\mathrm{IU} / \mathrm{L})$ & $12.6 \pm 2.3$ & $11.4 \pm 2.8$ & 0.01 \\
Alkaline phosphatase $(\mathrm{IU} / \mathrm{L})$ & $95.4 \pm 61$ & $146.7 \pm 80.4$ & 0.92 \\
Erythrocyte sedimentation rate $(\mathrm{mm} / \mathrm{h})$ & $13.8 \pm 3.3$ & $13.6 \pm 5.5$ & \\
\hline
\end{tabular}

*; Fisher's exact test, tTG: tissue transglutaminase

evidence from other diseases support a link between fever and autoimmune reactions. In fact, inflammatory cytokines can trigger leukocytes and other immune cells to promote the synthesis of pyrogens. ${ }^{10}$ In one study on children with a family history of diabetes mellitus, fever episodes (either associated or independent of infections) within the first year of life predicted autoimmunity against pancreatic cells. ${ }^{9}$ In another study with patients with scrub typhus infection, ANA autoantibodies developed within one week after initiation of fever. ${ }^{11}$ These reports support our findings regarding that fever can be a trigger for development of auto-antibodies; however, the clinical significance and persistency of various autoantibodies should be further scrutinized in various clinical conditions.

Among immune cells, neutrophils have been known as major contributors to inflammatory fever associated with various infections.
Neutrophils exposed to $45^{\circ} \mathrm{C}$ express a higher activity for 5-lipoxygenase, an enzymes involved in leukotriene synthesis. ${ }^{12}$ Although fever-like temperatures have been shown to prevent lipopolysaccharide-induced activation of NF- $\kappa \mathrm{B}$ transcription factor ${ }^{13,14}$, neutrophils can promote the production of autoantibodies (e.g. anti-neutrophil cytoplasmic autoantibodies) through NF- $\kappa B-$ independent signaling pathways as well. ${ }^{15}$ On the other hand, fever-like temperatures were noted to activate NF- $\kappa B$ pathway in macrophages. ${ }^{16}$ Fever range temperatures also induce $\mathrm{T}$ lymphocytes to produce stress proteins (such as heat-shock proteins-Hsp). ${ }^{17,18}$ In particular, Hsp90 protein can regulate $\mathrm{T}$ lymphocytes trafficking in feverish conditions. ${ }^{17}$ Following infection with type A streptococcus bacteria, an interaction between interleukin-1 $\beta$ granulocyte-macrophage colony-stimulating factor resulted in the proliferation of CD4+ T helper 1 lymphocytes. These events have been 
suggested to participate in autoimmunity observed in acute rheumatic fever following group A streptococcal infections. ${ }^{19,20}$ The roles of new identified mediators such as complement factor $5 \mathrm{a}$ and platelet-activating factor in fever induced immunity is yet to be divulged. ${ }^{21}$ In a reciprocal manner, autoimmunity may be itself a reason for fever. ${ }^{22}$ This is further supported by some reports noting that autoimmunity ${ }^{23,24}$ and lymphoproliferative disorders ${ }^{25}$ can be associated with fever of unknown origin. Fever can also regulate toll-like receptor (TLR) signaling pathways, ${ }^{16}$ cytoplasmic phospholipase $2,{ }^{26}$ intercellular adhesion molecule 1 (ICAM-1), and CCL21 chemokine. ${ }^{27}$

We could not explain an isolated significant decrease in ALP in patients with anti-tTG positivity accompanying normal levels of AST and ALT with no significant deviations in other tests. This observation may be a basis for checking the fluctuations of this enzyme in these patients in future studies.

We showed that fever can transiently trigger anti-tTG $\operatorname{IgA}$ autoantibody production in children which probably is promoted by modulating cellular and humoral immunities. Based on these findings, it is recommended to pediatricians to be vigilant in interpreting anti-tTG IgA results during fever episodes and repeat positive cases after the cease of fever. It is recommended to reassess the association of anti-tTG IgA seropositivity with fever in other clinical settings in future studies as well.

\section{REFERENCES}

1. Ogoina D. Fever, fever patterns and diseases called 'fever'--a review. J Infect Public Health 2011; 4: 108124.

2. Romanovsky AA, Steiner AA, Matsumura K. Cells that trigger fever. Cell Cycle 2006; 5: 2195-2197.

3. Ziemssen T, Kern S. Psychoneuroimmunology-cross-talk between the immune and nervous systems. J Neurol 2007; 254 (Suppl 2): II8-II11.

4. Netea MG, Kullberg BJ, Van der Meer JW. Circulating cytokines as mediators of fever. Clin Infect Dis 2000; 31 (Suppl 5): S178-S184.
5. Conti B, Tabarean I, Andrei C, Bartfai T. Cytokines and fever. Front Biosci 2004; 9: 1433-1449.

6. Jiang Q, Cross AS, Singh IS, Chen TT, Viscardi RM, Hasday JD. Febrile core temperature is essential for optimal host defense in bacterial peritonitis. Infect Immun 2000; 68: 1265-1270.

7. Cunha BA. Fever myths and misconceptions: the beneficial effects of fever as a critical component of host defenses against infection. Heart Lung 2012; 41: 99-101.

8. Horwitz MS, Ilic A, Fine C, Balasa B, Sarvetnick $\mathrm{N}$. Coxsackieviral-mediated diabetes: induction requires antigen-presenting cells and is accompanied by phagocytosis of beta cells. Clin Immunol 2004; 110: 134-144.

9. Beyerlein A, Wehweck F, Ziegler AG, Pflueger M. Respiratory infections in early life and the development of islet autoimmunity in children at increased type 1 diabetes risk: evidence from the BABYDIET study. JAMA Pediatr 2013; 167: 800-807.

10. Johnson Rowsey P. Thermoregulation: cytokines involved in fever and exercise. Annu Rev Nurs Res 2013; 31: 19-46.

11. Koshy M, Mathew J, Alex R, et al. Antinuclear antibodies in scrub typhus: transient occurrence during acute illness. J Vector Borne Dis 2018; 55: 5257.

12. Werz O, Bürkert E, Samuelsson B, Rådmark O, Steinhilber D. Activation of 5-lipoxygenase by cell stress is calcium independent in human polymorphonuclear leukocytes. Blood 2002; 99: 1044-1052.

13. Kettritz R, Choi M, Salanova B, Wellner M, Rolle S, Luft FC. Fever-like temperatures affect neutrophil NF-kappaB signaling, apoptosis, and ANCA-antigen expression. J Am Soc Nephrol 2006; 17: 1345-1353.

14. Lee JJ, Huang WT, Shao DZ, Liao JF, Lin MT. Blocking NF-kappaB activation may be an effective strategy in the fever therapy. Jpn J Physiol 2003; 53: 367-375.

15. von Vietinghoff S, Choi M, Rolle S, Luft FC, Kettritz R. Febrile temperatures control antineutrophil cytoplasmic autoantibody-induced neutrophil activation via inhibition of phosphatidylinositol 3-kinase/Akt. Arthritis Rheum 2007; 56: 3149-3158.

16. Zhao W, An H, Zhou J, Xu H, Yu Y, Cao X. Hyperthermia differentially regulates TLR4 and TLR2-mediated innate immune response. Immunol Lett 2007; 108: 137-142.

17. Lin $\mathrm{CD}$, Zhang $\mathrm{YH}$, Zhang $\mathrm{K}$, et al. Fever promotes $\mathrm{T}$ lymphocyte trafficking via a thermal sensory pathway involving heat shock protein 90 and $\alpha 4$ integrins. Immunity 2019; 50: 137-151.e6. 
18. Singh IS, Hasday JD. Fever, hyperthermia and the heat shock response. Int J Hyperthermia 2013; 29: 423-435.

19. Cunningham MW. Post-Streptococcal autoimmune sequelae: rheumatic fever and beyond. In: Ferretti JJ, Stevens DL, Fischetti VA (eds). Streptococcus pyogenes: Basic Biology to Clinical Manifestations. Oklahoma City (OK): University of Oklahoma Health Sciences Center, 2016: 863-929.

20. Kim ML, Martin WJ, Minigo G, et al. Dysregulated IL-1beta-GM-CSF axis in acute rheumatic fever that is limited by hydroxychloroquine. Circulation 2018; 138: 2648-2661.

21. Garami A, Steiner AA, Romanovsky AA. Fever and hypothermia in systemic inflammation. Handb Clin Neurol 2018; 157: 565-597.

22. Alqahtani M, Mukundan D. Current understanding of fever and host immunity. Curr Opin Pediatr 2011; 23: $115-120$.
23. Pourabbas B, Geramizadeh B, Dashti AS, et al. AntiMDA5-positive dermatomyositis presenting as fever of unknown origin. J Gen Intern Med 2016; 31: 15301536.

24. Blockmans D, Bossuyt L, Degreef H, van den Oord JJ, Knockaert D, Bobbaers H. Linear IgA dermatosis: a new cause of fever of unknown origin. Neth J Med 1995; 47: 214-218.

25. Cunha BA, Petelin AP, Turi GK, Oraji A. Fever of unknown origin (FUO) attributable to indolent lymphoproliferative disorder due to a plasmacytoma expressing immunoglobulin A. Heart Lung 2012; 41: 404-406.

26. Steiner AA, Ivanov AI, Serrats J, et al. Cellular and molecular bases of the initiation of fever. PLoS Biol 2006; 4: e284.

27. Chen Q, Fisher DT, Clancy KA, et al. Fever-range thermal stress promotes lymphocyte trafficking across high endothelial venules via an interleukin 6 trans-signaling mechanism. Nat Immunol 2006; 7: 1299-1308. 